\title{
Vertebrate sex determination: many means to an end
}

\author{
Bronwyn C. Morrish and Andrew H. Sinclair* \\ Murdoch Children's Research Institute, Royal Children's Hospital, \\ Flemington Rd, Melbourne, Victoria 3052, Australia
}

\begin{abstract}
The differentiation of a testis or ovary from a bipotential gonadal primordium is a developmental process common to mammals, birds and reptiles. Since the discovery of $S R Y$, the Y-linked testis-determining gene in mammals, extensive efforts have failed to find its orthologue in other vertebrates, indicating evolutionary plasticity in the switch that triggers sex determination. Several other genes are known to be important for sex determination in mammals, such as SOX9, AMH, WT1, SF1, DAX1 and DMRT1. Analyses of these genes in humans with gonadal dysgenesis, mouse models and using in vitro cell culture assays have revealed that sex determination results from a complex interplay between the genes in this network. All of these genes are conserved in other vertebrates, such as chickens and alligators, and show gonad-specific expression in these species during the period of sex determination. Intriguingly, the sequence, sex specificity and timing of expression of some of these genes during sex determination differ among species. This finding indicates that the interplay between genes in the regulatory network leading to gonad development differs between vertebrates. However, despite this, the development of a testis or ovary from a bipotential gonad is remarkably similar across vertebrates.
\end{abstract}

The existence of two sexes is nearly universal in the animal kingdom and although gonadal morphogenesis is remarkably similar across vertebrates, the sex-determining mechanism varies considerably. In most mammals, including humans, mice and marsupials, sexual fate is determined genetically by the presence of the $S R Y$ gene (sex-determining region on the $\mathrm{Y}$ chromosome; Sry in mice), which encodes the testis-determining factor on the $\mathrm{Y}$ chromosome (Sinclair et al., 1990; Koopman et al., 1991). Similarly, avian sex is determined genetically, although unlike mammals, the heterogametic sex in birds is female (ZW sex chromosomes), whereas males are homogametic (ZZ sex chromosomes). To date, it is not clear whether the sexdetermining mechanism in birds is a dominant ovarydetermining gene residing on the $\mathrm{W}$ chromosome or whether a double dose of a Z-linked gene triggers testis determination (for a review, see Clinton, 1998). The genetic switch in birds may involve both $\mathrm{W}$ - and Z-chromosomebased mechanisms. In contrast to mammals and birds, reptiles such as the American alligator do not have dimorphic sex chromosomes. Instead, this species uses temperature-dependent sex determination; all eggs incubated at $32.5-33.0^{\circ} \mathrm{C}$ during the sex-determining period become male and most eggs incubated outside these temperatures become female (Lang and Andrews, 1994). Hormones are also critical for sex determination in birds

*Correspondence

Email: sinclair@cryptic.rch.unimelb.edu.au and alligators. Ectopic administration of oestrogen or inhibitors of oestrogen synthesis during a critical period of gonadogenesis in chickens and alligators can feminize or masculinize the gonads, respectively, regardless of chromosomal or environmental cues (Lance and Bogart, 1991, 1992; Elbrecht and Smith, 1992; Vaillant et al., 2001).

\section{Gonadal development in vertebrates}

\section{Mouse}

The first sign of gonadogenesis in mice is the formation of the urogenital system from the intermediate mesoderm, which begins at about day 9.0-9.5 after mating. At about day 10.5 after mating, the paired urogenital system runs much of the length of the embryo and fills most of the coelomic cavity. The urogenital system is composed of three segments from anterior to posterior: the pronephros (includes the adrenal primordium), the mesonephros (the embryonic kidney) and the metanephros (the primordium of the definitive kidney). The Wolffian duct is derived from lateral mesoderm and runs the length of the urogenital system. The Müllerian duct appears between day 11.5 and day 12.5 after mating from invagination of surface epithelium from the mesonephros and runs parallel to the Wolffian duct. In females, the Müllerian duct differentiates into the oviduct, uterus and upper parts of the vagina, but is regressed in males by the action of the anti-Müllerian hormone, $\mathrm{AMH}$. In females, the Wolffian duct will mostly degenerate, but in males, testosterone secreted by testicular 


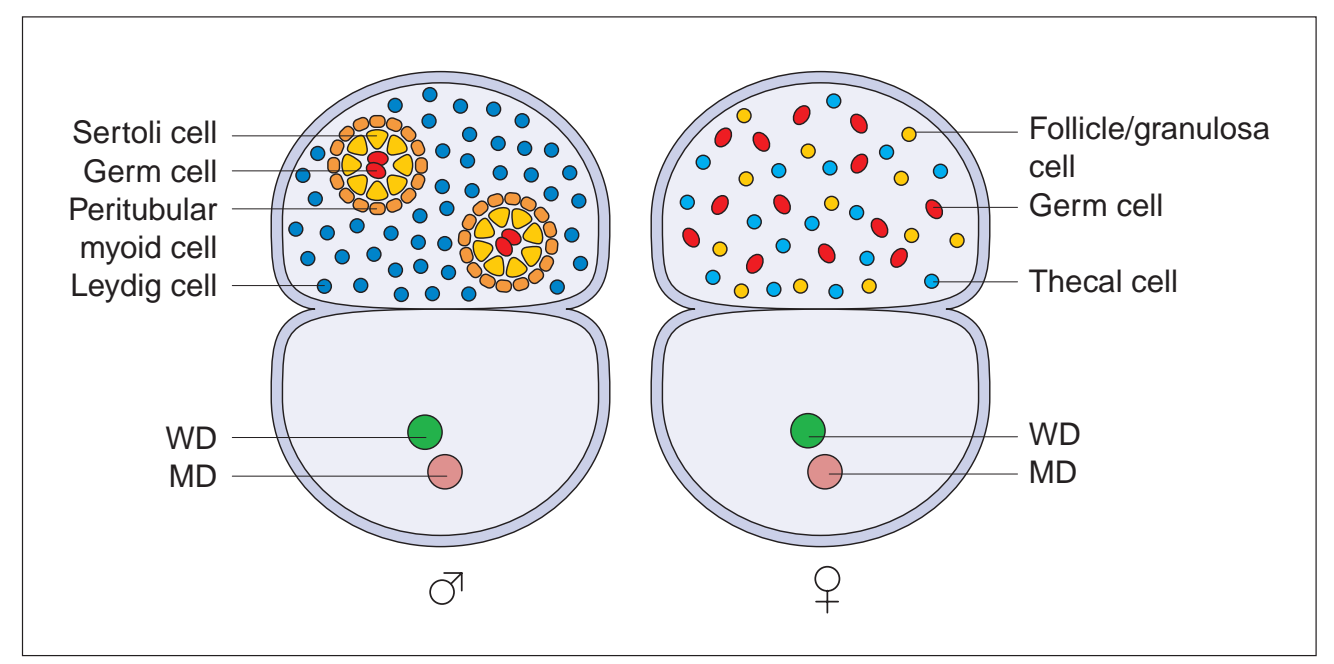

Fig. 1. Schematic diagram of a cross-section through an embryonic mouse testis and ovary with adjacent mesonephros at day 12.5 after mating. MD: Müllerian duct; WD: Wolffian duct. In the male gonad, the testis cords are composed of the peritubular myoid cells, the Sertoli cells and the germ cells.

Leydig cells will induce the Wolffian duct to differentiate into the epididymis, vas deferens and seminal vesicles.

From about day 10.5 after mating, the bipotential gonadal primordium arises from the ventromedial surface of the mesonephros as a proliferating layer of coelomic epithelial cells. In male mice, expression of Sry begins at day 10.5 after mating, reaches a peak at day 11.5 after mating and then ceases abruptly by day 12.5 after mating (Hacker et al., 1995). The exact mode of action and immediate targets of SRY are unknown, but the consequence of Sry expression is the rapid induction of morphological changes in male gonads, which clearly distinguishes them from female gonads by day 12.5 after mating (Fig. 1). At this stage, the male gonad is twice the size of the female gonad and is composed of highly structured testis cords surrounded by interstitium. In males, the germ cells are enclosed by the supporting cell lineage, the Sertoli cells (the supporting cells in the ovary are the granulosa/follicle cells). The Sertoli cells are surrounded by basal lamina and peritubular myoid cells, which result in the characteristic cord morphology of the testis. The interstitium of the testis includes the steroidogenic cell lineage, the Leydig cells (theca cells in the ovary) and prominent vascularization. In contrast, the female gonad at day 12.5 after mating is smaller and less well organized than the testis (Fig. 1). In the developing ovary at day 12.5 after mating, the germ cells reside in the interstitium with the supporting and steroidogenic cells, and no prominent vascularization or structural tissue is visible. The appearance of ovigerous cords (egg clusters) in the ovary occurs at about day 15.5 after mating and the oocyte becomes surrounded by granulosa cells to form the primordial follicle just before birth.

One of the most important functions of Sry is thought to be the induction of differentiation of Sertoli cells in the testis. Sry induces increased proliferation of coelomic epithelial cells, which can be first detected from day 11.5 after mating (Schmahl et al., 2000). Sertoli cells and some of the interstitial cells derive from the proliferating coelomic epithelial cells that delaminate from the surface and migrate into the gonad (Karl and Capel, 1998). Sry also induces the migration of cells from the mesonephros into the developing gonad (Capel et al., 1999). These mesonephrically derived cells become the peritubular myoid cells, which interact with the Sertoli cells to lay down the basement membrane, thereby forming the testis cords. Mesonephrically derived cells also make up the vasculature and other regions within the interstitium (Martineau et al., 1997).

Germ cells behave very differently during male and female gonadogenesis. In both sexes, the germ cells migrate from the allantois to the coelomic epithelium of the gonad via the gut mesentery between day 9.5 and day 11.0 after mating, where they proliferate until day 12.5 after mating. At this stage in the male, the germ cells are enclosed within the testis cords and enter mitotic arrest. The germ cells in females continue to undergo mitosis until day 13.5 after mating, when they enter meiotic arrest (McLaren and Southee, 1997). Meiotic germ cells in females are essential for formation and maintenance of the ovarian follicles (McLaren, 1995). The interaction between germ cells and the supporting cells is thought to play a critical part in sex determination. Sertoli cells that surround the germ cells in the testis cords are thought to prevent the male germ cells from entering meiosis.

\section{Chicken}

At day 3.5 (stage 22) in chicken embryogenesis, the gonadal primordium begins forming. By day 5.5 (stage 28), the bipotential gonad has formed and both left and right 


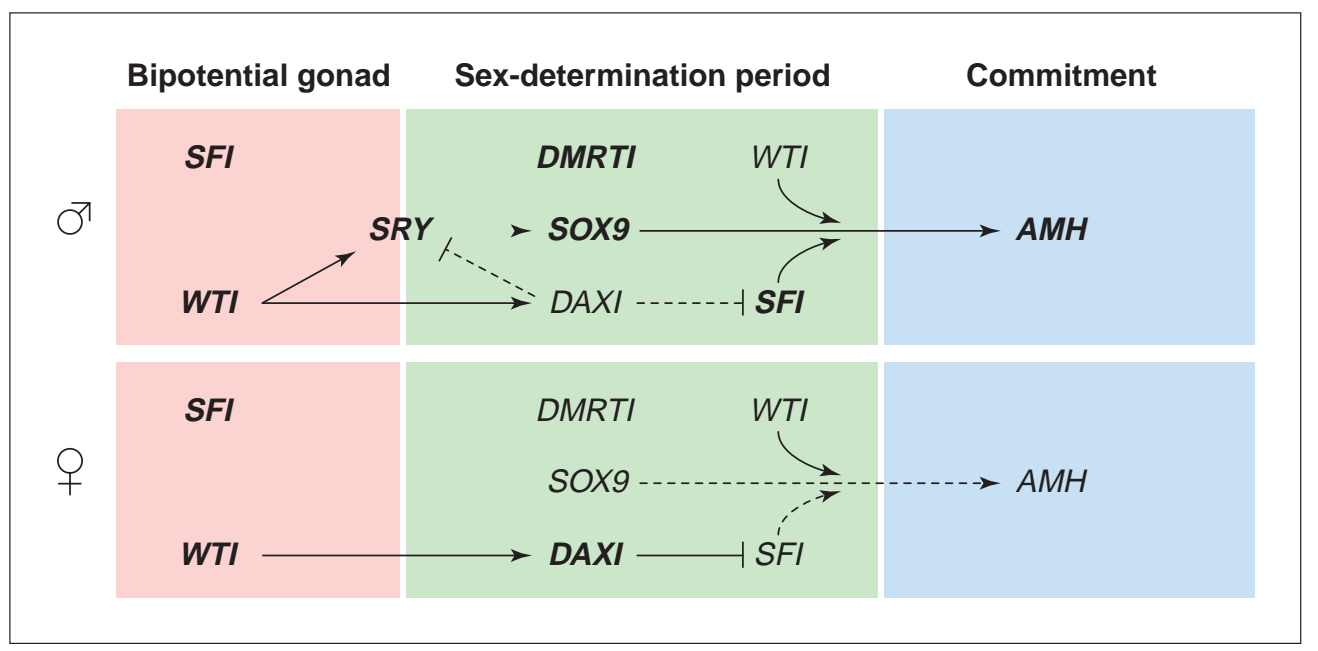

Fig. 2. Known and postulated gene regulatory pathways during gonadogenesis. Upregulated genes are depicted in bold. Arrow on line indicates positive regulation. Bar on line indicates inhibitory interaction. Solid lines indicate strong interactions and dashed lines indicate weak interactions. SF1: steroidogenic factor 1; WT1: Wilms' tumour suppressor gene; SRY: sexdetermining region on the $\mathrm{Y}$ chromosome; DMRT1: doublesex- and mab-3-related transcription factor 1; SOX9: Sry-like HMG box; DAX1: dosage sensitive sex-reversal-adrenal hypoplasia congenita-critical region of the $\mathrm{X}$ chromosome, gene $1 ; A M H$ : anti-Müllerian hormone.

urogenital systems appear identical in males and females. The sexes can be distinguished morphologically by day 6.5 (stage 30) and testis cord formation is complete in males by day 7.5 (stage 32). One of the striking differences between mammalian and avian gonadogenesis is the left-right asymmetry of chicken gonads. By day 8.5 (stage 35), only the left ovary of the female has developed (the right regresses to a vestige) and the right testis of the male is slightly smaller than the left. In both sexes, there are more germ cells in the larger left gonad. The bipotential gonad in chickens is composed of proliferating coelomic epithelial cells that contain most of the germ cells and an underlying medulla. During male gonadogenesis, there is a proliferation of cells within the medulla and a reduction in the thickness of the coelomic epithelium. Sertoli cells differentiate within the medulla and enclose the germ cells in characteristic testis cords. In females, the coelomic epithelial cells proliferate to form the cortex, which contains the germ cells, whereas the medulla fragments (for a review, see Smith and Sinclair, 2001).

\section{Alligator}

The sex of many reptiles, including that of all crocodilians so far examined, is determined by temperature. For the American alligator, Alligator mississippiensis, embryogenesis in eggs incubated at $33^{\circ} \mathrm{C}$ produces all male offspring and takes approximately 64 days (Lang and Andrews, 1994). In contrast, embryogenesis in eggs incubated at $30^{\circ} \mathrm{C}$ produces all female offspring and takes approximately 70 days. At $33^{\circ} \mathrm{C}$, the first signs of testis differentiation are seen between day 28 and day 34 (stages 21-23), with the appearance of pre-Sertoli cells within the medulla. These cells proliferate and differentiate to initiate testis cord formation and enclose the germ cells between day 35 and day 41 (stages 23-24) (Smith and Joss, 1993). Ovarian differentiation at $30^{\circ} \mathrm{C}$ occurs later, from day 39 (stage 22), with proliferation of the germ cells and pre-granulosa cells in the cortex. Fragmentation of the medulla and formation of oogenital nests within the cortex occur by day 43 (stage 23). The temperature-sensitive period for sex determination in alligators occurs over a period of about 10 days, between stage 21 and stage 24 . After this time, the morphogenesis of the gonad will be irreversibly committed to either the male or female fate.

\section{Genes involved in gonadal differentiation in vertebrates}

Many genes affecting sex determination have been described in mice (for a review, see Swain and Lovell-Badge, 1999). Many of these genes were cloned in an attempt to identify the genes responsible for gonadal dysgenesis in humans, thus defining their role in the process of sex determination. The function of most of these genes has been further studied using mouse transgenic models and cell culture assays, revealing that sex determination results from the interplay of genes in a complex network (Fig. 2). Although several of these genes are broadly conserved in sequence and sites of expression among vertebrates, there are differences in their sexual dimorphism, timing of expression and putative functional domains. These differences may impinge on the interconnectivity of the gene network and could underscore some of the biological differences in sex determination between vertebrates. In this review, 
SOX9, AMH, WT1, SF1 and DMRT1, which are broadly male- or testis-specific and are expressed during or before testis determination in mice, and DAX1, which is upregulated in the female gonad during the period of sex determination in mice, will be discussed.

\section{SOX9 and $\mathrm{AMH}$}

The commitment to Sertoli cell differentiation in the mouse testis is considered the most significant aspect of Sry function. The transcription factor, Sox9 (Sry-like HMG box), is the earliest known marker of differentiating Sertoli cells and is therefore postulated to be an immediate downstream target of Sry, although this has not yet been shown experimentally. Anti-Müllerian hormone (AMH) is the first known protein to be secreted by differentiated Sertoli cells in the testis. Thus, Sox9 and Amh are two key components of mammalian testis determination and testis differentiation, respectively.

Humans with heterozygous mutations in SOX9 develop a severe bone disorder, called campomelic dysplasia. Seventy-five per cent of $X Y$ campomelic dysplasia patients display some degree of gonadal dysgenesis, indicating that SOX9 may have an important role in testis development. In contrast, ovarian development in XX campomelic dysplasia patients is normal (Foster et al., 1994). Moreover, the consequences of heterozygous SOX9 mutations are thought to result from haploinsufficiency rather than dominant negative effects, supporting the idea that dosage of SOX9 is critical for testis determination in humans (Olney et al., 1999).

SOX9 is a member of the large family of developmentally regulated SOX genes that are related by virtue of sharing $>50 \%$ amino acid identity with the DNA-binding HMG box of SRY (Prior and Walter, 1996). Apart from the DNAbinding HMG box, SOX9 in mice and humans contains two transcriptional activation domains, indicating that it is a typical transcription factor (Wright et al., 1995).

In mice, Sox9 expression is first detected in the bipotential gonads of both sexes at day 10.5 after mating (Fig. 3a; Kent et al., 1996). However, soon after the onset of Sry expression, Sox9 expression is upregulated in the male gonad and downregulated in the female gonad, so that from day 11.5 after mating, no Sox9-specific mRNA can be detected in the female gonad (Kent et al., 1996; Morais da Silva et al., 1996). At day 11.5 after mating in XY gonads, SOX9 protein is detected in the cytoplasm and nucleus of Sertoli cell precursors, whereas from day 11.5 after mating SOX9 is detected only in the nucleus of Sertoli cells (Morais da Silva et al., 1996). After birth, Sox9 expression persists in the Sertoli cells through to adulthood, but it is never detected in the ovary.

Mutations in $\mathrm{SOX} 9$ result in sex reversal and demonstrate that SOX9 is necessary for testis determination. However, SOX9 is also sufficient for testis determination, as an extra dose of SOX9 resulting from a chromosomal duplication causes male sexual development of an XX individual
(Huang et al., 1999). This has been further demonstrated in transgenic XX mice overexpressing Sox9, which develop normal testes (Vidal et al., 2001). To date, there are no reports of the gonadal phenotype of transgenic mice carrying null mutations in Sox9.

In mice, Amh expression is first detected from day 11.5 after mating in the male gonad, as the differentiated Sertoli cells start to align into cords (Fig. 3a; Hacker et al., 1995). From day 12.5 after mating, Amh is highly expressed in males and cannot be detected in females (Münsterberg and Lovell-Badge, 1991). Amh expression is downregulated in males after birth and is not detected in females until day 6 after birth. Mice carrying homozygous deletions in the Amh coding region have normally developed testis, but are infertile due to persistence of Müllerian-derived structures that interfere with sperm transfer (Behringer et al., 1994). Therefore, although Amh is important for the formation of secondary sexual characteristics, it is not required for testis determination.

Several lines of evidence indicate that $A M H$ transcription may be positively regulated by $S O X 9$ (Fig. 2). First, the $A M H$ promoter contains a consensus HMG-binding site that binds SOX9 in vitro (de Santa Barbara et al., 1998). AMH is positively transcriptionally regulated by SOX9 in transiently transfected cultured cells (de Santa Barbara et al., 1998). Transgenic mice carrying mutations in both copies of the putative SOX9-binding site in the endogenous Amh gene have a phenotype indistinguishable from that of mice carrying deletions of the Amh coding region (Arango et al., 1999). Finally, some $X Y$ sex-reversed humans with mutations in SOX9 have Müllerian duct-derived structures and are therefore unlikely to have produced AMH (Foster et al., 1994). It should be noted that although the evidence that SOX9 regulates AMH is compelling, it is not conclusive, as SOX9 has not been shown to bind the $A M H$ promoter in vivo. The $A M H$ promoter also has binding sites for the SF1 transcription factor and GATA family members (Shen et al., 1994; Viger et al., 1998). SF1 interacts with SOX9 to transactivate the $A M H$ promoter in vitro (de Santa Barbara et al., 1998). However, although targeted disruption in mice of the SF1 binding site in the endogenous Amh promoter reduces amounts of Amh mRNA by more than threefold compared with wild-type controls, Müllerian duct regression proceeds as normal (Arango et al., 1999). This finding demonstrates that very low amounts of $\mathrm{AMH}$ permit its function and highlights the importance of complete repression of Amh expression during female gonadal development.

SOX9 is highly conserved at the amino acid level and the gene shows testis-specific upregulation in all vertebrates examined to date. This finding indicates that SOX9 may represent an ancestral sex-determining gene and that mammals have subsequently evolved $S R Y$ as a Y-linked switching mechanism. Several studies have examined the expression of SOX9 in chickens using RT-PCR and RNA in situ hybridization on whole mounts and sections with some conflicting results regarding its onset of expression (Fig. 3b; 


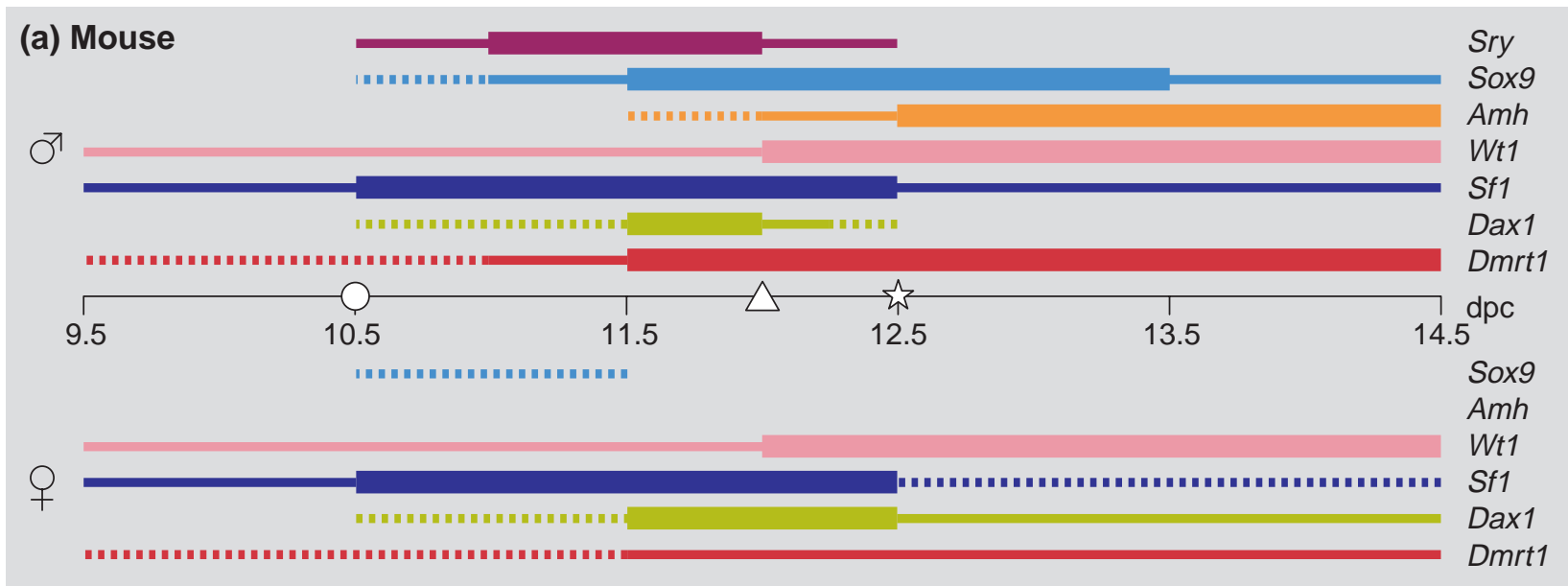

(b) Chicken

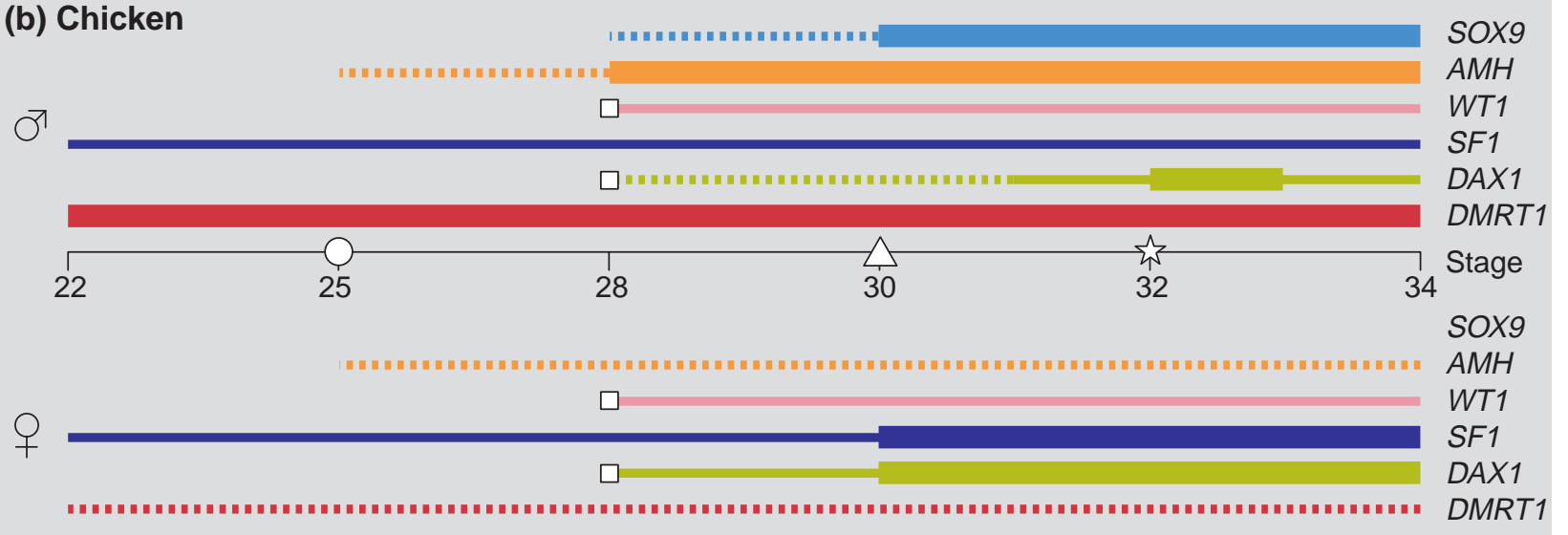

(c) Alligator

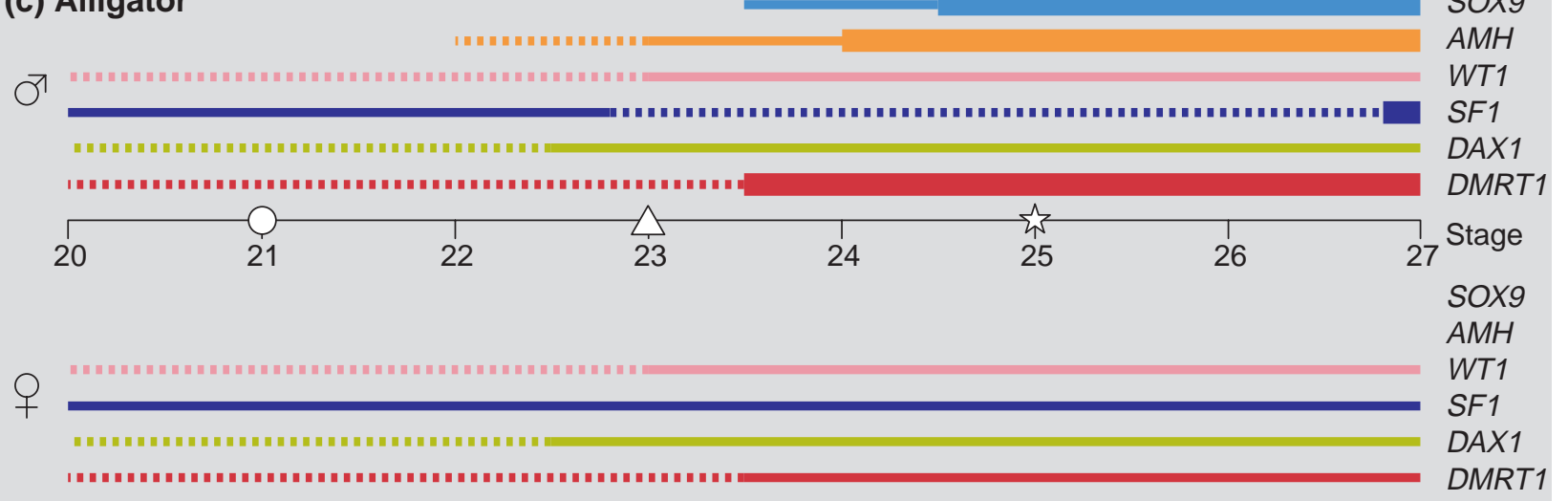

$\bigcirc$ Bipotential gonad $\triangle \mathrm{TC}$ formation begins $i s \mathrm{TC}$ formation complete $\quad \square$ Earliest time tested

Fig. 3. Relative gene expression in male and female gonads during the period of sex determination of embryogenesis in (a) mouse, (b) chicken and (c) alligator. Dotted lines indicate low expression; thin lines indicate moderate expression and thick lines indicate strong expression. The relative levels of expression for a given gene are comparable between the sexes of a given species and not between species or between genes in the same species. SRY: sex-determining region on the Y chromosome; SOX9: Sry-like HMG box; AMH: anti-Müllerian hormone; WT1: Wilms' tumour suppressor gene; SF1: steroidogenic factor 1; DAX1: dosage sensitive sex-reversal-adrenal hypoplasia congenita-critical region of the $\mathrm{X}$ chromosome, gene 1; DMRT1: doublesex- and mab-3-related transcription factor 1; dpc: days post coitus; TC: testis cord. 
Kent et al., 1996; Morais da Silva et al., 1996; Oreal et al., 1998; Smith et al., 1999a). Onset of SOX9 expression in both sexes from stage 25 was observed using RNA in situ hybridization on whole mounts (Morais da Silva et al., 1996). However, using RNA in situ hybridization on sections, SOX9 was first detected in males from stage 28 onwards (Oreal et al., 1998). However, two other studies (one using RT-PCR) failed to detect SOX9 expression in male gonads before stage 30 or in the female gonad at any stage (Kent et al., 1996; Smith et al., 1999a). The consensus from these studies is that SOX9 mRNA is not detected in the female gonad, although it is strongly expressed in the male gonad from stage 30 . The inconsistencies in the interpretation of the onset of SOX9 expression may reflect differences in the methods and probes used by the different groups.

In alligators, RT-PCR and RNA in situ hybridization on sections demonstrate that expression of SOX9 mRNA is upregulated in the gonads of embryos raised at maleproducing temperatures during stage 23 (Fig. 3c; Western et al., 1999a). The male-specific upregulation of SOX9 expression occurs at the end of the temperature-sensitive period, after Sertoli-like cells have started aligning into cords. Therefore, SOX9 upregulation in the male alligator occurs about 10 days after the signal to initiate malespecific differentiation of the gonad (Western et al., 1999a).

In chickens, $A M H$ expression can be detected from stage 25 in both sexes, at a time when SOX9 expression cannot be detected (Fig. 3b; Oreal et al., 1998). AMH expression is strongly upregulated in males from stage 28, at a time when weak SOX9 expression is first being detected. However, at stage 28 in females, weak $A M H$ expression can still be detected within the inner part of the gonad (the medulla), whereas SOX9 expression cannot be detected (Oreal et al., 1998). In another study using RT-PCR, AMH expression was detected from stage 28 in both male and female gonads, before first detection of SOX9, and was strongly upregulated in males at stage 30, when SOX9 expression was first detected (Smith et al., 1999a). At all times, $A M H$ expression was much higher in males than in females. Both studies in chickens indicate that the timing of $A M H$ expression precedes that of SOX9 in the developing gonad by about 1 day and that weak $A M H$ expression in females occurs in the absence of SOX9 expression.

In alligators, $A M H$ expression also appears to precede SOX9 expression (Fig. 3c; Western et al., 1999b). RT-PCR and RNA in situ hybridization on serial sections of alligator gonads were used to show that $A M H$ expression begins in males at stage 22 and reaches a peak at stage 24, whereas SOX9 expression was not detected until stage 23.5, 8 days after the onset of $A M H$ expression. As with mice and in contrast to chickens, $A M H$ expression was not detected in female gonads at any stage during alligator gonadogenesis.

In summary, SOX9 appears to have a pivotal role in the initial steps of Sertoli cell differentiation in mice, yet it is unlikely to perform the same function in other vertebrates, such as chickens and alligators. In fact, in alligators, preSertoli cells appear from stage 21, approximately 2 weeks before SOX9 can be detected. In mice, Sox 9 expression precedes Amh expression by about $24 \mathrm{~h}$ and Sox 9 is likely to regulate $A m h$ directly. In chickens and alligators, $A M H$ expression precedes SOX9 expression by about $24 \mathrm{~h}$ and 10 days, respectively, making it highly unlikely that SOX9 initiates $A M H$ expression. However, in both chickens and alligators strong upregulation of $A M H$ in males is coincident with the onset of SOX9 expression. This finding indicates that although $S O X 9$ does not initiate $A M H$ in these species, it may have a role in its subsequent upregulation. Moreover, in both mice and chickens, $A M H$ expression in females occurs in the absence of SOX9 expression.

In mice and alligators, morphological changes that distinguish the male gonad from the female gonad precede $A M H$ expression, indicating that $A M H$ expression is a good marker for differentiated Sertoli cells. In chickens, $A M H$ is first detected at stage 25 (or stage 28), 48 (or 24) h before any histological sign of testis morphogenesis (at stage 30 ). If $A M H$ expression is a universal marker for differentiated Sertoli cells, then in chickens Sertoli cells must differentiate before stage 25 , which would place the sex-determining event in chickens before stage 25 (day 4.5). Alternatively, Sertoli cell differentiation may occur closer to the time of morphological differentiation, at about the time of onset of SOX9 expression between stage 28 and stage 30 . In the latter scheme, $A M H$ could be expressed in both Sertoli and granulosa cell precursors and the low amounts would not be incompatible with female development. Indeed, $\mathrm{AMH}$ in female chicken gonads is postulated to be required for regression of the right Müllerian duct.

\section{Wilms' tumour suppressor gene (WT1)}

WT1 is required in mammals to establish the bipotential gonad and also plays a later role in testis development. WT1 is mutated in patients with Denys-Drash and Frasier syndromes. Individuals with these syndromes display abnormal urogenital development and XY sex reversal, supporting a role for $W T 1$ in gonadogenesis and testis determination (Pelletier et al., 1991a; Barbaux et al., 1997).

In mammals, WT1 is a complex gene comprising ten exons that can generate 24 possible isoforms by use of alternative start sites, splicing and RNA editing. Alternative splicing in exon nine results in isoforms with or without three amino acids, KTS, between the third and fourth zinc fingers. The KTS triplet results in the loss of DNA binding by the fourth zinc finger. The +KTS isoforms are commonly localized with splicing factors and may play a role in RNA processing, whereas the -KTS isoforms are considered transcription factors that can activate or repress transcription. Humans with Frasier syndrome have a splice-site mutation in WT1 that results in the production of only -KTS isoforms.

In mice, Wt1 is first detected from day 9.5 after mating throughout the intermediate mesoderm, encompassing the primordial mesonephros, gonads, kidneys and adrenal gland (Fig. 3a; Armstrong et al., 1992). In the bipotential 
gonad at day 10.5 after mating, Wt1 expression is detected in the somatic cells of the coelomic epithelium of both sexes, then later in the Sertoli cells of the male gonad and in the granulosa and epithelial cells of the female gonad (Pelletier et al., 1991b). During gonadogenesis in the rat embryo, RNase protection was used to show that concentrations of both WT1 isoforms are similar between males and females (Nachtigal et al., 1998).

The WT1-KTS can bind and transactivate the $S R Y$ and Dax1 promoters in vitro (Fig. 2; Kim et al., 1999; Hossain and Sanders, 2001). Although the WT1-KTS isoforms cannot bind to the $A M H$ promoter, it has been shown to synergize with SF1 to activate $A M H$ transcription in vitro (Nachtigal et al., 1998). In XX individuals, DAX1 is thought to interfere with the interaction of SF1 and WT1, thus repressing male-specific development (Fig. 2; Nachtigal et al., 1998).

Knockout mice carrying homozygous deletions of Wt1 die during mid-gestation and lack gonads, kidneys and adrenal glands, and have heart and spleen defects. Transgenic mice carrying only +KTS (-KTS isoforms ablated) or only -KTS (+KTS isoforms ablated) isoforms of Wt1 die shortly after birth from kidney defects (Hammes et al., 2001); however, the gonads of these mice display markedly different phenotypes, which is indicative of distinct functions for each isoform in gonadal development and sex determination. The gonads of mice carrying only +KTS isoforms fail to develop beyond streaks and undergo apoptosis. Patches of cells in the streak gonads of XY individuals still express some markers of testis determination (such as Sox9 and Amh), indicating that-KTS isoforms may be required for formation of the bipotential gonad rather than testis determination. Mice expressing only -KTS isoforms develop gonads, but all $X Y$ individuals are sexreversed, indicating that + KTS isoforms may be essential for testis determination, but not for ovarian development or formation of the bipotential gonad. The expression of Sry is markedly lower in mice carrying only -KTS isoforms, indicating that +KTS isoforms may be normally required for Sry expression (Hammes et al., 2001). This observation is consistent with the phenotype of XY Frasier patients, who develop sex-reversed gonads, but is in contrast to data obtained from in vitro studies indicating that only -KTS isoforms can transactivate the $S R Y$ promoter (Hossain and Saunders, 2001). It would appear that -KTS isoforms are essential for formation of the bipotential gonad, but that + KTS isoforms are required to allow enough expression of Sry to 'tip the balance' towards testis differentiation.

In chickens, RT-PCR was used to show that there is high expression of WT1 in both male and female gonads from stage 28 to stage 40, before and during gonadal differentiation (Fig. 3b; Smith et al., 1999a). In alligator gonads, WT1 expression can be detected by RT-PCR at stage 20, and expression is high from stage 23 at both male- and femaleproducing temperatures, but like in chickens, there is no sexual dimorphism in expression (Fig. 3c; Western et al., 2000). These studies did not distinguish between the different isoforms of WT1 that may be critical for sex determination.

In summary, the expression of WT1 in the early stages of chicken and alligator gonadogenesis supports a conserved function for WT1 across vertebrates during the time at which establishment of the gonadal primordium occurs, before sex determination. In mice, the different isoforms play distinct roles in gonadogenesis and testis determination, and there is now good evidence from studies in vivo that $W t 1$ enhances expression of Sry. At present, there are no data from other vertebrates addressing a role for WT1 in activating the expression of the sex-determination switch or in the sex-specific regulation of downstream genes.

\section{Steroidogenic factor 1 (SF1)}

SF1 (Ad4BP) is required in mammals for formation of the primary steroidogenic organs: the adrenal gland and the gonad. SF1 is also likely to have a role in testis development. Mutation in human SF1 results in XY gonadal dysgenesis and adrenal failure (Achermann et al., 1999). SF1 is an orphan nuclear receptor (ligand unknown) and has a DNA-binding domain comprising two highly conserved zinc fingers.

During mouse embryogenesis, Sf1 is expressed in the urogenital systems of both sexes from about day 9 after mating (Fig. 3a). Sf1 is detected in the somatic cells of the coelomic epithelium that go on to become the Sertoli and interstitial cells (presumably Leydig cells) of the male and the granulosa cells in females (Ikeda et al., 1994; Shen et al., 1994; Schmahl et al., 2000). From day 12.5 after mating, expression in male gonads persists in both the Sertoli and Leydig cells, but its expression is downregulated in females from day 13.5 after mating (lkeda et al., 1994). Sf1 expression is not high in females again until late gestation, when it is localized to the thecal cells of the ovary.

$S F 1$ positively regulates many genes involved in steroidogenesis, including genes encoding aromatase and $3 \beta$ hydroxysteroid dehydrogenase, which are involved in oestrogen and testosterone production by the gonadal steroidogenic cell lineages (for a review, see Parker and Schimmer, 1997). SF1 also regulates the expression of nonsteroidal genes in the testis, such as $A M H$ (see previous section). SF1 synergizes with WT1 and interacts with SOX9 to transactivate the $A M H$ promoter in vitro (de Santa Barbara et al., 1998; Nachtigal et al., 1998). DAX1 can recruit the co-repressor $\mathrm{N}-\mathrm{CoR}$ to SF1 in vitro, thus reducing its activity (Crawford et al., 1998).

Knockout mice carrying homozygous deletions of Sf1 lack gonads and adrenals and die shortly after birth. In these mice, the gonads begin to form, are colonized by germ cells, but cease development at day 11.0-11.5 after mating and then undergo apoptosis (Luo et al., 1994). Therefore, it is thought that Sf1 is important for creating an environment suitable for somatic cell proliferation, differentiation and maintenance, rather than for gonad formation and testis determination per se. 
In all vertebrates examined to date, expression of SF1 is observed in the gonadal primordium before sex determination, supporting a role for SF1 in establishing a functional bipotential gonad. However, changes in the relative amounts of SF1 in male and female gonads during the sex determination period are remarkably variable among species. In the Red-eared slider turtle (Trachemys scripta), a species that uses temperature-dependent sex determination, SF1 expression is maintained in males and downregulated in females during the temperature-sensitive period (Fleming et al., 1999). However, in alligators, which also use temperaturedependent sex determination, SF1 expression is maintained in females and downregulated in males from stage 23, during the temperature-sensitive period (Fig. 3c; Western et al., 2000). In chickens, SF1 expression is maintained in males, but is upregulated in females during the period of sex determination (Fig. 3b; Smith et al., 1999a,b).

In chickens and alligators, high SF1 in the ovaries is probably correlated with the higher steroidogenic activity of the embryonic ovary compared with the testis in these species. Specifically, high SF1 in the ovary possibly reflects its involvement in the stimulation of aromatase expression, which is critical for normal ovarian development in chickens and alligators (Elbrecht and Smith, 1992; Lance and Bogart, 1992). In mice, aromatase is not expressed until late in ovarian development, so ovarian development is largely independent of oestrogen synthesis. Therefore, in mice, increased Sf1 expression in the testis compared with the ovary presumably reflects its important role in Sertoli and Leydig cell function in production of $\mathrm{AMH}$ and testosterone, respectively.

The $A M H$ promoter has a consensus SF1 binding site in all species examined to date (de Santa Barbara et al., 1998; Oreal et al., 1998). SF1 has a role in upregulating Amh in mice, and SF1 expression in the male gonads of chickens and alligators during the period of sex determination may reflect a conserved role for it in the regulation of $A M H$. As SF1 is expressed before the onset of $A M H$ expression in chickens and alligators, it may initiate $A M H$ expression in these species. However, there must be other factors involved, as SF1 is expressed well before $A M H$ is detected in both chickens and alligators. Furthermore, other factors must contribute to the expression of $A M H$ in the male gonads of chickens and alligators, as SF1 expression is higher in females than males at the time when $A M H$ expression is higher in males than females. SOX9 is an attractive candidate for regulating the expression of $A M H$ in the male gonads of chickens and alligators. However, sexually dimorphic $A M H$ expression precedes SOX9 expression in chickens and alligators, indicating that additional genes are probably required.

\section{Dosage sensitive sex reversal (DAX1)}

$D A X 1$ (dosage sensitive sex-reversal-adrenal hypoplasia congenita-critical region of the $X$ chromosome, gene 1 ) is an X-linked gene in humans, which when duplicated results in $\mathrm{XY}$ sex reversal. Mutations in $D A X 1$ are responsible for adrenal hypoplasia congenita $(\mathrm{AHC})$ in humans. $D A X 1$ is a member of the orphan nuclear hormone receptor family, comprising a conserved C-terminal ligand-binding domain, but possessing three-and-a-half tandem copies of a 67 amino acid repeat, instead of the classical zinc-finger DNA binding domain.

During mouse embryogenesis, Dax1 expression is first detected from day 10.5 after mating throughout the gonadal primordium of both sexes (Fig. 3a). Dax1 expression is upregulated in both sexes from day 11.5 after mating and its expression is subsequently downregulated in males from day 12.5 after mating, but persists in females throughout ovarian development (Swain et al., 1996, 1998). Dax1 is expressed in the somatic cells of the bipotential gonad of both sexes. After sex determination, Dax 1 is expressed in the Sertoli and Leydig cells of the testis and in the somatic cells of the ovary (Ikeda et al., 1996; Swain et al., 1996; Tamai et al., 1996). However, Dax1 expression is restricted to the testicular Leydig cells and ovarian thecal and granulosa cells in late embryonic development and during adulthood (Ikeda et al., 1996; Swain et al., 1996). The dynamic temporal and spatial expression of Dax 1 within the male and female gonads during embryogenesis and beyond indicates that it may perform multiple functions.

Dax 1 is proposed to be an antagonist of Sry function in males, as both genes are expressed in the same tissues and at the same time (Swain et al., 1998). Furthermore, coexpression of Dax1 and Sry from the Dax 1 promoter in transgenic mice results in $100 \% \mathrm{XX}$ females, whereas transgenic $\mathrm{XX}$ animals carrying only the Sry transgene develop as males (Swain et al., 1998). Dax1 is also expressed in the same tissues as $S f 1$, including the adrenal gland, gonad, hypothalamus and pituitary, indicating that they may act in the same developmental pathway (Ikeda et al., 1996). Several in vitro studies support a role for DAX1 protein in the inhibition of SF1-mediated transcriptional activation (Ito et al., 1997; Zazopoulos et al., 1997; Crawford et al., 1998; Nachtigal et al., 1998). These studies have proposed a number of mechanisms by which DAX1 and SF1 might function, so the exact nature of the DAX1-SF1 interaction in vivo remains unclear at present. It is unclear whether DAX1 exerts a repressive effect on SF1 due to direct protein-protein interactions, recruitment of co-repressors or by DNA binding. It is possible that distinct combinations or all of these functions may operate in vivo under different cellular and developmental conditions. To date, all DAX1 mutations detected in patients with $\mathrm{ACH}$ localize to the $\mathrm{C}$-terminal part of the gene, so it is likely that this region represents the critical domain for $D A X 1$ function in vivo.

Male mice overexpressing Dax 1 can develop as females, but only in the presence of a late acting or 'weak' Sry allele (Swain et al., 1998). However, Dax 1 is considered to be an 'anti-testis' gene, rather than a ovary-determining gene, as XX mice carrying homozygous deletions of Dax1 develop as normal females (Yu et al., 1998). These mice also display 
compromised endocrine function, indicating that Dax1 may play a more critical role in the endocrine function of the gonad, rather than in sex determination.

In chickens and alligators, the DAX1 C-terminal putative ligand-binding domain shows high amino acid identity with the same region in mammals (Smith et al., 2000; Western et al., 2000). However, chicken and alligator DAX1 lack the $\mathrm{N}$ terminal tandem repeat regions containing the putative DNA binding domain in mammalian $D A X 1$ (although chicken and alligator $D A X 1$ amino acid sequences align quite well in this region). The lack of conservation of the $\mathrm{N}$-terminal region might reflect a divergence in function of DAX1 between mammals compared with chickens and alligators.

In chicken gonads, RNase protection assays were used to show DAX 1 expression at stage 28 in both sexes before sex determination (Fig. 3b; Smith et al., 2000). DAX1 expression increases between stage 28 and stage 30 in females, and continues to increase until at least stage 36. DAX1 expression also increases in male gonads after stage 30 , but amounts are always markedly lower than in females and decrease significantly by stage 35, after the sex-determining period (Smith et al., 2000). In chickens, the sexually dimorphic expression of DAX1 is consistent with that observed in mice, but unlike the situation in mice, $D A X 1$ is not downregulated in males at the onset of sexual differentiation, but is downregulated afterwards. RT-PCR on gonadal samples from alligator embryos raised at maleand female-producing temperatures showed that $D A X 1$ was upregulated from stage 23, during the temperature-sensitive period, but was not sexually dimorphic during gonadogenesis (Fig. 3c; Western et al., 2000).

A role for $D A X 1$ repressing testis development in chickens is consistent with its increased expression in the gonads of females compared with males during the sex-determining period, but this remains to be demonstrated. In alligators, the timing of $D A X 1$ expression is consistent with a function in sex determination, but if DAX1 is performing an anti-testis function in alligators, other factors must also be involved, as $D A X 1$ is not female-specific. The available evidence in mice suggests that Dax 1 is inhibitory to $S f 1$ action. However, it is possible that in chickens and alligators, DAX1 performs the opposite function; it may augment SF1-mediated transcription of steroidogenic genes such as aromatase and hence promote ovarian development. To date, the role of $D A X 1$ in the regulation of steroidogenic genes in chickens and alligators remains to be investigated.

\section{DMRT1}

DMRT1 (doublesex- and mab-3-related transcription factor 1 is the best conserved sex-determining gene in metazoans. DM-containing genes in Caenorhabditis elegans (mab-3) and Drosophila melanogaster ( $d s x$ ) are also involved in differentiation of the gonads and encode transcription factors that are thought to bind DNA through their DM domains (Raymond et al., 1998).

In mice, Dmrt1 expression is detected by day 9.5 after mating (Fig. 3a). From day 10.5 after mating, Dmrt1 is expressed exclusively in the bipotential gonads of both sexes. From day 12.5 after mating, Dmrt1 transcripts are localized to the Sertoli and germ cells of the testis and in a punctate pattern in the ovaries (Raymond et al., 1999). By day 14.5 after mating, Dmrt1 expression is clearly higher in the testis compared with the ovary and by day 15.5 after mating, it is only weakly detected in the ovary.

Although it is clear that the expression of DMRT1 is gonad-specific, it has not been established whether it has a role in sex determination. Humans carrying deletions of chromosome 9 that include DMRT1 are XY sex-reversed (Veitia et al., 1997). However, at least two other DM-related genes map to the same region of chromosome 9 that is deleted in these sex-reversed individuals. Several studies have failed to find distinct mutations in the DMRT1 gene of humans with $X Y$ sex reversal. Mice carrying homozygous deletions of Dmrt1 are not $X Y$ sex-reversed, but they are infertile, due to severe testicular failure and defects in proliferation of germ cells (Raymond et al., 2000). To date, no upstream regulators or downstream targets of DMRT1 have been identified, making it impossible to place DMRT1 in any gene regulatory pathway.

In chickens, DMRT1 is located on the $\mathrm{Z}$ sex chromosome and its transcripts are detected from stage 19 (Raymond et al., 1999). DMRT1 is upregulated in male gonads compared with female gonads as early as stage 22, well before any morphological differentiation of the gonads (Fig. 3b; Raymond et al., 1999; Smith et al., 1999c; Smith and Sinclair, 2001; C. Smith and A. Sinclair, unpublished). The increased expression in males is greater than the twofold that would be expected from having two expressed copies and therefore its upregulation in males is likely to be specifically regulated.

In alligators, DMRT1 expression is detected from stage 20 in both sexes from the earliest stages of gonadogenesis (Fig. 3c; Smith et al., 1999c). DMRT1 expression increases between stage 23 and stage 24 in the gonads of both sexes, but is greater in the gonads of embryos incubated at maleproducing temperatures. Hence, Dmrt1 represents a widely conserved male-upregulated gene.

In summary, although Dmrt1 is not likely to be involved in testis determination in mice, its chromosomal localization and tissue-, temporal- and sex-specific expression make it a strong candidate for a testis-determining factor in chickens. However, other genes must be required to initiate testis differentiation in males, as DMRT1 is expressed in both sexes well before the sex-determining period. Thus, $D M R T 1$ is unlikely to represent an SRY-like 'switch' in chickens. The same is true in alligators, as DMRT1 is present in both sexes before the temperature-sensitive period and is upregulated in males only towards the end of the temperature-sensitive period.

\section{Conclusion}

Mice, chickens and alligators use distinct mechanisms to initiate the cascade of genes that determines the sexual fate 
of the bipotential gonad. The genes described in this review represent some of the key sex-determining genes known in mice. These genes are also expressed during gonadogenesis in chickens and alligators, but the timing of expression relative to the critical sex-determining period, sequences and the sexual dimorphism of their expression vary considerably among the different species. This finding indicates that the interplay between these genes in mammalian sex determination might differ in other species. Despite this, morphological development of the testis and ovary is remarkably similar across these species.

Work in our laboratory is funded by grants from the NH\&MRC and the Murdoch Children's Research Institute. The authors would like to gratefully acknowledge Craig Smith and Peter McClive for critical reading of this manuscript and to thank the Education Resource Centre at the Royal Children's Hospital for creating the figures used in this review.

\section{References}

Key references are identified by asterisks.

Achermann JC, Ito M, Hindmarsh PC and Jameson JL (1999) A mutation in the gene encoding steroidogenic factor- 1 causes $X Y$ sex reversal and adrenal failure in humans Nature Genetics 22 125-126

Arango NA, Lovell-Badge R and Behringer RR (1999) Targeted mutagenesis of the endogenous mouse Mis gene promoter: in vivo definition of genetic pathways of vertebrate sexual development Cell 99 409-419

Armstrong JF, Pritchard-Jones K, Bickmore WA, Hastie ND and Bard JB (1992) The expression of the Wilms' tumour gene, WT1, in the developing mammalian embryo Mechanisms of Development $\mathbf{4 0}$ 85-97

Barbaux S, Niaudet P, Gubler MC et al. (1997) Donor splice-site mutations in WT1 are responsible for Frasier syndrome Nature Genetics 17 $467-470$

Behringer RR, Finegold M and Cate RL (1994) Müllerian-inhibiting substance function during mammalian sexual development Cell $\mathbf{7 9}$ $415-425$

Capel B, Albrecht KH, Washburn LL and Eicher EM (1999) Migration of mesonephric cells into the mammalian gonad depends on Sry. Mechanisms of Development 84 127-131

Clinton M (1998) Sex determination and gonadal development: a bird's eye view Journal of Experimental Zoology 281 457-465

Crawford PA, Dorn C, Sadovsky Y and Milbrandt J (1998) Nuclear receptor DAX-1 recruits nuclear receptor corepressor $\mathrm{N}-\mathrm{CoR}$ to steroidogenic factor 1 Molecular and Cellular Biology 18 2949-2956

*de Santa Barbara P, Bonneaud N, Boizet B, Desclozeaux M, Moniot B, Sudbeck P, Scherer G, Poulat F and Berta P (1998) Direct interaction of SRY-related protein SOX9 and steroidogenic factor 1 regulates transcription of the human anti-Müllerian hormone gene Molecular and Cellular Biology 18 6653-6665

Elbrecht A and Smith RG (1992) Aromatase enzyme activity and sex determination in chickens Science 255 467-470

Fleming A, Wibbels T, Skipper JK and Crews D (1999) Developmental expression of steroidogenic factor 1 in a turtle with temperaturedependent sex determination General and Comparative Endocrinology $116336-346$

Foster JW, Dominguez-Steglich MA, Guioli S et al. (1994) Campomelic dysplasia and autosomal sex reversal caused by mutations in an $S R Y$ related gene Nature $\mathbf{3 7 2}$ 525-530

Hacker A, Capel B, Goodfellow P and Lovell-Badge R (1995) Expression of Sry, the mouse sex determining gene Development 121 1603-1614

Hammes A, Guo JK, Lutsch G, Leheste JR, Landrock D, Ziegler U, Gubler MC and Schedl A (2001) Two splice variants of the Wilms' tumor 1 gene have distinct functions during sex determination and nephron formation Cell 106 319-329

Hossain A and Saunders GF (2001) The human sex-determining gene SRY is a direct target of WT1 Journal of Biological Chemistry 27616817 16823

Huang B, Wang S, Ning Y, Lamb AN and Bartley J (1999) Autosomal XX sex reversal caused by duplication of SOX9 American Journal of Medical Genetics 87 349-353

Ikeda Y, Shen WH, Ingraham HA and Parker KL (1994) Developmental expression of mouse steroidogenic factor-1, an essential regulator of the steroid hydroxylases Molecular Endocrinology 8 654-662

Ikeda Y, Swain A, Weber TJ et al. (1996) Steroidogenic factor 1 and Dax-1 colocalize in multiple cell lineages: potential links in endocrine development Molecular Endocrinology 10 1261-1272

Ito $\mathbf{M}, \mathbf{Y u} \mathbf{R}$ and Jameson JL (1997) DAX-1 inhibits SF-1-mediated transactivation via a carboxy-terminal domain that is deleted in adrenal hypoplasia congenita Molecular and Cellular Biology 17 1476-1483

Karl J and Capel B (1998) Sertoli cells of the mouse testis originate from the coelomic epithelium Developmental Biology 203 323-333

*Kent J, Wheatley SC, Andrews JE, Sinclair AH and Koopman P (1996) A male-specific role for SOX9 in vertebrate sex determination Development 122 2813-2822

Kim J, Prawitt D, Bardeesy N, Torban E, Vicaner C, Goodyer P, Zabel B and Pelletier J (1999) The Wilms' tumor suppressor gene (wt1) product regulates Dax-1 gene expression during gonadal differentiation Molecular and Cellular Biology 19 2289-2299

*Koopman P, Gubbay J, Vivian N, Goodfellow P and Lovell-Badge R (1991) Male development of chromosomally female mice transgenic for Sry. Nature 351 117-121

Lance V and Bogart M (1991) Tamoxifen 'sex reverses' alligator embryos at male producing temperatures but is an antiestrogen in female hatchlings Experimentia 47 263-266

Lance VA and Bogart MH (1992) Disruption of ovarian development in alligator embryos treated with an aromatase inhibitor General and Comparative Endocrinology 86 59-71

Lang JW and Andrews HV (1994) Temperature-dependent sex determination in crocodilians Journal of Experimental Zoology $27028-44$

Luo X, Ikeda Y and Parker KL (1994) A cell-specific nuclear receptor is essential for adrenal and gonadal development and sexual differentiation Cell 77 481-490

McLaren A (1995) Germ cells and germ cell sex Philosophical Transactions of the Royal Society of London, Series B: Biological Sciences $\mathbf{3 5 0}$ 229-233

McLaren A and Southee D (1997) Entry of mouse embryonic germ cells into meiosis Developmental Biology 187 107-113

Martineau J, Nordqvist K, Tilmann C, Lovell-Badge R and Capel B (1997) Male-specific cell migration into the developing gonad Current Biology 7 958-968

* Morais da Silva S, Hacker A, Harley V, Goodfellow P, Swain A and LovellBadge R (1996) Sox9 expression during gonadal development implies a conserved role for the gene in testis differentiation in mammals and birds Nature Genetics 14 62-68

Münsterberg A and Lovell-Badge R (1991) Expression of the mouse antiMüllerian hormone gene suggests a role in both male and female sexual differentiation Development 113 613-624

*Nachtigal MW, Hirokawa Y, Enyeart-VanHouten DL, Flanagan JN, Hammer GD and Ingraham HA (1998) Wilms' tumor 1 and Dax-1 modulate the orphan nuclear receptor SF-1 in sex-specific gene expression Cell 93 445-454

Olney PN, Kean LS, Graham D, Elsas LJ and May KM (1999) Campomelic syndrome and deletion of SOX9 American Journal of Medical Genetics 84 20-24

*Oreal E, Pieau C, Mattei MG, Josso N, Picard JY, Carre-Eusebe D and Magre S (1998) Early expression of AMH in chicken embryonic gonads precedes testicular SOX9 expression Developmental Dynamics 212 $522-532$

Parker KL and Schimmer BP (1997) Steroidogenic factor 1: a key determinant of endocrine development and function Endocrine Reviews $18361-377$ 
Pelletier J, Bruening W, Kashtan CE et al. (1991a) Germline mutations in the Wilms' tumor suppressor gene are associated with abnormal urogenital development in Denys-Drash syndrome Cell 67 437-447

Pelletier J, Schalling M, Buckler AJ, Rogers A, Haber DA and Housman D (1991b) Expression of the Wilms' tumor gene WT1 in the murine urogenital system Genes and Development 5 1345-1356

Prior HM and Walter MA (1996) SOX genes: architects of development Molecular Medicine 2 405-412

Raymond CS, Shamu CE, Shen MM, Seifert KJ, Hirsch B, Hodgkin J and Zarkower D (1998) Evidence for evolutionary conservation of sexdetermining genes Nature 391 691-695

*Raymond CS, Kettlewell JR, Hirsch B, Bardwell VJ and Zarkower D (1999) Expression of Dmrt1 in the genital ridge of mouse and chicken embryos suggests a role in vertebrate sexual development Developmental Biology 215 208-220

Raymond CS, Murphy MW, O'Sullivan MG, Bardwell VJ and Zarkower D (2000) Dmrt1, a gene related to worm and fly sexual regulators, is required for mammalian testis differentiation system Genes and Development 14 2587-2595

Schmahl J, Eicher EM, Washburn LL and Capel B (2000) Sry induces cell proliferation in the mouse gonad Development 127 65-73

Shen WH, Moore CC, Ikeda Y, Parker KL and Ingraham HA (1994) Nuclear receptor steroidogenic factor 1 regulates the Müllerian inhibiting substance gene: a link to the sex determination cascade Cell 77 651-661

*Sinclair AH, Berta P, Palmer MS et al. (1990) A gene from the human sexdetermining region encodes a protein with homology to a conserved DNA-binding motif Nature 346 240-244

Smith CA and Joss JMP (1993) Gonadal sex differentiation in Alligator mississippiensis, a species with temperature-dependent sex determination Cell and Tissue Research 273 149-162

Smith CA and Sinclair AH (2001) Sex determination in the chicken embryo Journal of Experimental Zoology $290691-699$

Smith CA, Smith MJ and Sinclair AH (1999a) Gene expression during gonadogenesis in the chicken embryo Gene 234 395-402

Smith CA, Smith MJ and Sinclair AH (1999b) Expression of chicken steroidogenic factor-1 during gonadal sex differentiation General and Comparative Endocrinology 113 187-196

*Smith CA, McClive PJ, Western PS, Reed KJ and Sinclair AH (1999c) Conservation of a sex-determining gene Nature 402 601-602

Smith CA, Clifford V, Western PS, Wilcox SA, Bell KS and Sinclair AH (2000) Cloning and expression of a DAX1 homologue in the chicken embryo Journal of Molecular Endocrinology 24 23-32

Swain A and Lovell-Badge R (1999) Mammalian sex determination: a molecular drama Genes and Development 13 755-767
Swain A, Zanaria E, Hacker A, Lovell-Badge R and Camerino G (1996) Mouse Dax1 expression is consistent with a role in sex determination as well as in adrenal and hypothalamus function Nature Genetics 12 404-409

Swain A, Narvaez V, Burgoyne P, Camerino G and Lovell-Badge R (1998) Dax1 antagonizes Sry action in mammalian sex determination Nature $391761-767$

Tamai KT, Monaco L, Alastalo TP, Lalli E, Parvinen M and Sassone-Corsi P (1996) Hormonal and developmental regulation of DAX-1 expression in Sertoli cells Molecular Endocrinology 10 1561-1569

Vaillant S, Dorizzi M, Pieau C and Richard-Mercier N (2001) Sex reversal and aromatase in chicken Journal of Experimental Zoology 290 $727-740$

Veitia R, Nunes M, Brauner R, Doco-Fenzy M, Joanny-Flinois O, Jaubert F, Lortat-Jacob S, Fellous M and McElreavey K (1997) Deletions of distal $9 p$ associated with $46 \mathrm{XY}$ male to female sex reversal: definition of the breakpoints at 9p233-p241 Genomics 41 271-274

Vidal VP, Chaboissier MC, de Rooij DG and Schedl A (2001) Sox9 induces testis development in XX transgenic mice Nature Genetics 28 216-217

Viger RS, Mertineit C, Trasler JM and Nemer M (1998) Transcription factor GATA-4 is expressed in a sexually dimorphic pattern during mouse gonadal development and is a potent activator of the Müllerian inhibiting substance promoter Development 125 2665-2675

Western PS, Harry JL, Graves JA and Sinclair AH (1999a) Temperaturedependent sex determination: upregulation of SOX9 expression after commitment to male development Developmental Dynamics $\mathbf{2 1 6}$ 171-177

*Western PS, Harry JL, Graves JA and Sinclair AH (1999b) Temperaturedependent sex determination in the American alligator: $A M H$ precedes SOX9 expression Developmental Dynamics 216 411-419

Western PS, Harry JL, Marshall Graves JA and Sinclair AH (2000) Temperature-dependent sex determination in the American alligator: expression of SF1, WT1 and DAX1 during gonadogenesis Gene $\mathbf{2 4 1}$ 223-232

Wright E, Hargrave MR, Christiansen J, Cooper L, Kun J, Evans T, Gangadharan U, Greenfield A and Koopman P (1995) The Sry-related gene Sox9 is expressed during chondrogenesis in mouse embryos Nature Genetics 9 15-20

Yu RN, Ito M, Saunders TL, Camper SA and Jameson JL (1998) Role of Ahch in gonadal development and gametogenesis Nature Genetics 20 353-357

Zazopoulos E, Lalli E, Stocco DM and Sassone-Corsi P (1997) DNA binding and transcriptional repression by DAX-1 blocks steroidogenesis Nature $390311-315$ 